\title{
BENTUK DAN DERAJAT LUKA PERINEUM IBU NIFAS DI WILAYAH KABUPATEN KLATEN
}

\author{
Triwik Sri Mulati \\ Kementerian Kesehatan Politeknik Kesehatan Surakarta Jurusan Kebidanan
}

\begin{abstract}
Perineum Laceration Type, Perineum Laceration Level, Post Partum Mother. The aim of this research was to know the descriptive of the type and the level of perineum laceration on post partum mother at Klaten. This research was descriptive design. The data were analyzed using descriptive statistics. The respondents were 84 post partum mothers who experienced perineum laceration but without complication. The result showed the majority of perineum laceration type was rupture (86.9\%) and the majority of perineum laceration level was $2^{\text {nd }}$ level (69\%).
\end{abstract}

Keywords: Perineum Laceration Type, Perineum Laceration Level, Post Partum Mother

Abstrak: Bentuk Luka Perineum, Derajat Luka Perineum, Ibu Nifas. Penelitian ini bertujuan untuk mengetahui gambaran bentuk dan derajat luka perineum ibu nifas di wilayah Kabupaaten Klaten. Jenis penelitian ini adalah diskriptif dan metode analisis data yang digunakan adalah deskriptive statistics. Sampel dalam penelitian ini yaitu ibu nifas yang mengalami luka perineum tapi yang tidak mengalami komplikasi sejumlah 84 orang. Hasil penelitian ini menunjukkan bentuk luka perineum sebagian besar responden adalah ruptur sebanyak $86.9 \%$ dan derajat luka perineum sebagian besar responden adalah robekan derajat 2 sejumlah $69 \%$.

Kata Kunci: Bentuk Luka Perineum, Derajat Luka Perineum, Ibu Nifas

\section{PENDAHULUAN}

Sebagian besar ibu akan mengalami kecemasan ketika menghadapi proses persalinan. Kecemasan tersebut disebabkan karena adanya stigma bahwa melahirkan itu akan terasa sakit dan bahkan akan melukai perineum. Faktanya banyak ibu bersalin yang mengalami luka pada perineumnya. Luka tersebut terjadi karena adanya tindakan medis yaitu pengguntingan pada perineum karena ada indikasi, yang biasa disebut tindakan episiotomi atau terjadi karena adanya robekan perineum secara alami yang lukanya tidak teratur yang disebabkan adanya desakan kepala janin yang terlalu cepat atau bahu pada proses persalinan
(Jones, 2006). Oleh karena itu bentuk luka perineum dibedakan menjadi 2 yaitu bentuk luka perineum ruptur dan episiotomi.

Luka perineum pada kenyataannya sering membuat ibu nifas sangat tidak nyaman bahkan mengalami ketakutan untuk melakukan mobilisasi dini. Padahal mobilisasi dini sangat penting untuk melancarkan pengeluaran lokea, mengurangi infeksi pada luka, mempercepat involusio alat kandungan, melancarkan peredaran darah, mencegah tromboplebitis dan akan mempercepat penyembuhan luka. Selain itu nyeri luka perineum akan mengganggu ibu berinteraksi dengan bayinya, membuat ibu 
lebih rentan terkena infeksi dan kemungkinan akan menyebabkan terjadinya perdarahan jika luka perineum tidak dipantau dengan baik. Nyeri luka perineum jelas akan menimbulkan dan mempengaruhi kesejahteraan perempuan secara fisik, psikologis dan sosial pada periode postnatal baik secara langsung maupun dalam jangka panjang (Rustam, 2008). Oleh karena itu akan lebih baik jika ibu bersalin bisa melahirkan tanpa mengalami laserasi/luka perineum.

Luka perineum ada yang ringan sampai berat. Robekan luka perineum dibedakan menjadi robekan derajat luka, dari robekan derajat 1 sampai robekan derajat 4. Tentu saja semakin dalam dan lebar luka perineum akan semakin menyebabkan nyeri. Bidan sebagai salah satu tenaga kesehatan yang bertugas menolong persalinan diharapkan mampu meminimalkan bahkan mencegah supaya ibu bersalin tidak mengalami luka perineum sehingga saat periode nifas, ibu tidak perlu merasakan nyeri luka perineum.

Survey pendahuluan yang dilakukan oleh peneliti di Desa Danguran, salah satu desa di wilayah Kabupaten Klaten, di temukan bahwa dari 5 ibu nifas, 4 orang mengalami luka perineum dengan klasifikasi robekan dari derajat 1 sampai 2. Berdasarkan survey pendahuluan tersebut, penulis tertarik meneliti gambaran bentuk dan derajat luka perineum pada ibu nifas di wilayah kabupaten Klaten.

Secara umum hasil penelitian ini diharapkan dapat memberikan informasi tentang bentuk dan derajat luka perineum yang dialami oleh ibu nifas di wilayah kabupaten Klaten. Secara rinci hasil penelitian ini diharapkan mampu menginspirasi para tenaga kesehatan penolong persalinan terutama bidan untuk meminimalkan dan mencegah terjadinya luka perineum saat proses persalinan demi mewujudkan kesejahteraan fisik dan psikologi ibu nifas beserta bayinya.

\section{METODE PENELITIAN}

Jenis penelitian ini adalah deskriptif, karena peneliti hanya mendeskripsikan bentuk dan derajat luka perineum pada ibu nifas di wilayah Kabupaten Klaten.

Sampel dalam penelitian ini adalah ibu nifas yang mengalami luka perineum tapi yang tidak ada kompikasi sejumlah 84 orang.

Instrument dalam penelitian ini adalah lembar observasi untuk mencatat bentuk dan derajat luka perineum. Analisis data dilakukan dengan menggunakan descriptive statistics.

\section{HASIL PENELITIAN}

Hasil penelitian yang berjudul bentuk dan derajat luka perineum ibu nifas di wilayah Kabupaten klaten dapat dideskripsikan sebagai berikut:

\section{Tabel 1}

Distribusi Frekuensi Karakteristik Responden Berdasarkan Umur

\begin{tabular}{lcc}
\hline \multicolumn{1}{c}{ Umur } & $\mathbf{N}$ & $\mathbf{\%}$ \\
\hline$<20$ & 3 & 3.6 \\
$20-35$ & 74 & 88 \\
$>35$ & 7 & 8.4 \\
\hline Total & 84 & 100 \\
\hline
\end{tabular}

Berdasarkan tabel 1 terlihat bahwa karakteristik responden berdasarkan umum, sebagian besar responden berada pada umur reproduksi sehat yaitu antara 20-35 sejumlah 74 orang ( $88 \%$ ). 
Tabel 2

Distribusi Frekuensi Karakateristik Responden Berdasarkan Paritas

\begin{tabular}{lcc}
\hline Umur & N & \% \\
\hline Primipara & 42 & 50 \\
Multipara & 42 & 50 \\
\hline Total & 84 & 100 \\
\hline
\end{tabular}

Berdasarkan tabel 2 terlihat bahwa karakteristik responden berdasarkan paritas sebagian besar adalah primipara (melahirkan anak yang pertama) sejumlah 42 orang $(50 \%)$ dan multipara (melahirkan anak yang ke dua, ketiga, dan keempat) sejumlah 42 orang (50\%).

Tabel 3.

Distribusi Deskriptif Bentuk Luka Perineum Responden

\begin{tabular}{lll}
\hline Bentuk Luka & $\mathrm{N}$ & $\%$ \\
\hline Episiotomi & 11 & 13.1 \\
Ruptur & 73 & 86.9 \\
\hline Total & 84 & 100 \\
\hline
\end{tabular}

Berdasarkan tabel 3 Terlihat bahwa sebagian besar bentuk luka perineum pada responden adalah ruptur perineum sejumlah 73 responden $(86.9 \%)$.

Tabel 4

Distribusi Deskriptif Derajat Luka Perineum Responden

\begin{tabular}{lcc}
\hline $\begin{array}{c}\text { Derajat } \\
\text { Luka }\end{array}$ & $\mathbf{N}$ & \% \\
\hline Derajat 1 & 22 & 26.2 \\
Derajat 2 & 58 & 69 \\
Derajat 3 & 3 & 3.6 \\
Derajat 4 & 1 & 1.2 \\
\hline Total & 84 & 100 \\
\hline
\end{tabular}

Berdasarkan tabel 4 ditunjukkan bahwa mayoritas derajat luka perineum responden pada klasifikasi robekan derajat 2 yaitu sejumlah 58 orang (69\%).

\section{PEMBAHASAN}

Hasil penelitian menunjukkan sebagian besar responden pada kategori umur reproduksi sehat. Hal tersebut sesuai teori bahwa seorang ibu akan sehat jika melahirkan pada umur antara 20-35 tahun karena pada saat itu organ reproduksi wanita dalam kondisi yang prima untuk menghadapi proses kehamilan dan kelahiran (Manuaba, 2007). Tetapi meskipun sebagian besar responden berada pada rentang umur reproduksi sehat, ternyata tidak mengurangi kejadian luka perineum karena sejumlah 73 responden $(86.9 \%)$ mengalami ruptur perineum. Hal tersebut bisa disebabkan karena responden saat hamil tidak melakukan pijat perineum sehingga perineum mereka kaku (perineum tidak lentur) dan mudah untuk terjadinya ruptur. Selain itu responden mungkin juga ada yang mengejan tidak sesuai teori sehingga pantat di angkat atau mengejan yang terlalu kuat sehingga menyebabkan robekan jalan lahir saat terdesak oleh kepala janin yang terlalu cepat. Hal ini sesuai dengan teori yang di kemukakan oleh Saleha (2009).

Sedangkan 11 responden $(13.1 \%)$ mengalami luka perineum akibat dari episiotomi. Episiotomi tersebut dilakukan karena adanya indikasi medis misalnya adanya janin besar. Untuk melancarkan kelahiran, agar janin bisa lahir sesuai waktu yang ideal (sesuai teori) maka perlu untuk memperbesar jalan lahir dengan melakukan tindakan episiotomi. Indikasi lainnya untuk dilakukan episiotomi adalah posisi kepala janin yang abnormal, kelahiran bokong, ekstraksi forsep yang sukar dan distosia bahu (Anggraini, 2010). Pada penelitian ini karena pengambilan data di tempat persalinan bidan praktek mandiri di wilayah kabupaten Klaten maka kebanyakan indikasi dari episiotomi adalah karena bayi besar.

Berdasarkan klasifikasi derajat luka, mayoritas responden mengalami 
robekan perineum derajat 2 yaitu sejumlah 58 orang $(69 \%)$. Robekan perineum derajat 2 di jelaskan bahwa luka perineum meliputi mucosa vagina, kulit perineum dan otot perineum. Perbaikan luka dilakukan setelah diberi anestesi lokal kemudian otot-otot diafragma urogenitalis dihubungkan di garis tengah dengan jahitan dan kemudian luka pada vagina dan kulit perineum ditutupi dengan mengikut sertakan jaringan - jaringan dibawahnya. Hal tersebut sesuai dengan teori yang di kemukakan oleh Saifuddin (2010).

Sedangkan sejumlah 22 responden (26.2 \%) mengalami robekan perineum derajat 1 yaitu luka perineumnya meliputi mukosa vagina, kulit perineum tepat dibawahnya. Umumnya robekan derajat 1 dapat sembuh sendiri. Penjahitan tidak diperlukan jika tidak perdarahan dan menyatu dengan baik (Saifuddin, 2010).

Tiga responden $(3.6 \%)$ mengalami robekan perineum derajat 3 yaitu luka perineumnya meliputi mukosa vagina, kulit perineum, otot perineum dan otot spingterani eksternal. Pada robekan partialis denyut ketiga yang robek hanyalah spingter. Pada luka perineum derajat 3 ini dibutuhkan penjahitan (Saifuddin, 2010). Luka perineum derajat 3 tersebut terjadi karena tindakan episiotomi dengan indikasi bayi besar.

Terlebih lagi robekan perineum derajat 4 harus dilakukan penjahitan karena luka perineumnya adalah robekan yang total dimana spingter recti terpotong dan laserasi meluas sehingga dinding anterior rektum dengan jarak yang bervariasi (Saifuddin, 2010). Untuk luka perineum derajat 4 ini dialami oleh 1 responden $(1.2 \%)$ karena ibu dilakukan episiotomi atas indikasi bayi besar.

\section{KESIMPULAN DAN SARAN}

Berdasar hasil analisis data dan pembahasan dapat disimpulkan sebagai berikut: (1) Mayoritas responden mengalami bentuk luka perineum ruptur, (2) Mayoritas responden mengalami robekan perineum derajat 2.

Saran yang diajukan yaitu supaya para penolong persalinan terutama para bidan untuk meningkatkan melatih ibu hamil aterm berlatih mengejan yang benar dan ibu bersalin di pimpin untuk mengejan yang benar, ibu hamil diajari untuk melakukan pijat perineum agar melenturkan perineum, mendeteksi dini kehamilan supaya tidak terjadi kehamilan dengan bayi besar. Para ibu hamil dan ibu bersalin dapat lebih kooperatif dengan para bidan sehingga tidak salah dalam mengejan.

\section{DAFTAR RUJUKAN}

Anggraini, Y. 2010. Asuhan Kebidanan Masa Nifas. Yogyakarta : Pustaka Rihama.

Manuaba, Ida Bagus Gde. 2007. Konsep Obstetri dan Ginekologi Sosial Indonesia. Jakarta : EGC.

Saifuddin. 2010. Buku Panduan Praktis Pelayanan Kesehatan Maternal dan Neonatal. Jakarta : EGC.

Saleha, S. 2009. Asuhan Kebidanan pada Masa Nifas. Jakarta : Salemba Medika.

Suherni. 2009. Perawatan Masa Nifas. Yogyakarta : Fitramaya. 